\title{
Chapter 12 \\ Key Issues in Understanding \\ and Improving Safety Culture
}

\author{
Stian Antonsen
}

\begin{abstract}
The aim of this chapter is to highlight three key issues that safety researchers and practitioners should consider as part of a cultural approach to the study and improvement of safety. The three issues are: (1) the relationship between integration and differentiation in safety culture research, (2) moving from descriptions of safety cultures to improvement of safety, and (3) the possible downsides of a cultural approach to safety. The chapter argues that a better understanding of boundary processes between groups is vital for a cultural approach to safety improvement and gives a set of general principles for the design of improvement initiatives. Some limits and limitations to the cultural approach to safety are also discussed.
\end{abstract}

Keywords Safety culture - Integration - Differentiation - Organizational boundaries - Safety improvement

\section{Introduction}

The concept of safety culture rose to prominence within safety management and safety research around the year 2000. Although the investigation of the Chernobyl accident is ubiquitously cited as being responsible for coining the term, the research origins date further back (e.g. Turner, 1978; Zohar, 1980). The genesis of the concept has been thoroughly described elsewhere (Cox \& Flin, 1998; Guldenmund, 2000; Antonsen, 2009a) and will not be repeated here. Rather, in this chapter, I will

S. Antonsen $(\bowtie)$

SINTEF, Trondheim, Norway

e-mail: Stian.Antonsen@sintef.no

(C) The Author(s) 2018

C. Gilbert et al. (eds.), Safety Cultures, Safety Models,

SpringerBriefs in Safety Management,

https://doi.org/10.1007/978-3-319-95129-4_12 
discuss what I believe to be key issues that should be part of practitioners' and researchers' efforts to adopt a cultural approach to safety improvement. ${ }^{1}$

When scholars and practitioners meet to discuss topics related to safety culture, there are three questions that tend to stand out in the discussions. One is the question of whether an organization can be regarded as having one overarching organizational (safety) culture, or if organizations are better understood by seeing them as consisting of several, sometimes conflicting, subcultures. The other question has to do with the way information and understanding of safety culture(s) can be turned into safety improvement. In this chapter I will reflect on these two questions on the basis of selected literature on organizational culture, as well as my own previous work on the topic. In addition, I will take the opportunity to discuss a third question: what are the possible unintended consequences of adopting a safety culture approach? As researchers and practitioners of risk management, we are trained to look for the different ways in which things may go wrong, and our own efforts of improvement should be no exception to such scrutiny.

\section{Integration and Differentiation in Organizational Culture Research}

The definition of safety culture has been one of the most widely-debated topics within the safety science research community. Guldenmund's (2000) review of the literature came up with nearly 20 different definitions of safety culture and safety climate, and in the years since his review several more has been proposed. Despite the variety of definitions, there are several recurring themes. One of them is that culture is something that is shared among the members of a social unit, and that it influences what is seen as meaningful ways to behave, communicate and interact. Taking this as a premise, two important questions arise: What are the units of analysis, and what is it that they actually share? These questions have to do with the relationship between integration and differentiation. There is a duality inherent in the concepts of group and culture in that it is both a matter of the internal integration within a group, and the construction of borders with other groups. Thus, understanding integration will most often involve understanding what distinguishes a group from their surroundings and other groups. When dealing with the theoretical and conceptual aspects of culture, this standpoint is fairly uncontroversial. However, for the study and improvement of safety in organizations over a certain size, it becomes more problematic. Is safety culture something that characterizes the organization in its entirety, or are we better off studying safety cultures in plural, thus viewing safety culture as belonging to groups, professions, departments,

\footnotetext{
${ }^{1}$ The issues raised in this chapter are by no means new to the field of safety science. They have previously been raised and discussed in different ways by authors like Frank Guldenmund, Andrew Hopkins, Knut Haukelid, Carl Rollenhagen and others.
} 
facilities etc. within the organizations? The obvious answer is that we should do both: we should both understand the general organizational frameworks that distinguish the organization from other organizations, and the differentiation, dynamics and power struggles between the different groups that comprise the organization as a whole. In order to do this, however, we should start by distinguishing between what is shared and what is not shared (Antonsen, 2009b). Safety culture research has been predominately oriented at describing the traits that are shared among the members of an organization. My proposal is to complement this picture by shifting the attention towards the construction of boundaries between groups, and the boundary maintenance ${ }^{2}$ that takes place in the interaction between members of groups. In the following sections, I will provide some examples of such boundaries within organizations before turning to a brief discussion of the elements that are likely to be shared across entire organizations.

What can be the possible sources of cultural boundaries within organizations? An organization over a certain size will need to have a horizontal division of labor and a vertical distribution of authority (Mintzberg, 1983) which involve the possibility of cultural differentiation. The division of labor means that people are responsible for different more or less specialized parts of the organization's production processes. Working with the same tasks can be a source of shared identity among the members of a community of practice (Wenger, 1998). The flipside of the coin is that people performing other tasks can be defined as outsiders to this specific community.

The vertical distribution of authority has previously been shown to be the source of cultural differentiation. Schein (1996), often cited as the prime exponent of purely integrative research on organizational culture, describes three different organizational strata which may form different subcultures in organizations: the executive culture, the engineering culture and the operator culture. These groups face different problems and tasks, are likely to have different experiences and perceptions about the organization's activity and may find themselves in conflict and power struggles. Similar descriptions of stratified subcultures have been presented in Johannessen's (2013) study of the Norwegian police and, to some extent, in Crozier's (1964) study of the relationship between workers and management in French industrial organizations.

In addition to, and across these two lines of differentiation, runs a third possible cultural boundary, consisting of the professional identities often shared by people with the same background in terms of education and basic training. Such lines of division are closely related to the previous two, but can cut across organizational strata, departments or even organizations. If you are a doctor, a seafarer, a pilot or a lawyer, you are likely to have some similarities in skills, knowledge or experience with people with the same background, and this can form the basis of dissimilarities.

\footnotetext{
${ }^{2}$ The term 'boundary maintenance' is borrowed from Barth's (1969) classic discussion of ethnic groups and boundaries.
} 
A last example of cultural boundaries in organization has to do with nationality and ethnicity. As patterns of mobility and migration change, so does the cultural complexity of large organizations. For instance, some studies of Polish construction workers in Norway and England show that there may be differences in the way different groups view the quality of work being performed, the way they interact with people from other groups, and the power distance between managers and superiors where these have different national origins (Wasilkiewicz, Albrechtsen, \& Antonsen, 2016; Datta \& Brickell, 2009).

The list of possible boundaries described here is by no means exhaustive. It is also important to note that there is no one-to-one relationship between the boundaries described, and cultural differentiation. The existence and nature of cultural differences is an empirical question, not an a priori one. A remaining question, however, concerns the relevance of such cultural boundaries for safety. The answers to this question have much to do with communication and the flow of information in the organization. Turner and Pidgeon launched the concept of "variable disjunction of information" to describe

a complex situation in which a number of parties handling a problem are unable to obtain precisely the same information about the problem, so that many differing interpretations of the situation exist. (Turner \& Pidgeon, 1997, p. 40)

Different people will have access to different information and will also have different frames of reference in interpreting information and situations. Thus, different groups of people will never have precisely the same interpretation of information and situations. This is both a source of requisite variety, and a challenge for organizational communication, interaction and decisions. In any case, knowledge about the various viewpoints of the groups, and the way information is translated when it crosses cultural boundaries, is important knowledge for those aiming to understand and improve the conditions for safety in the organization. For instance, some of the communication across cultural boundaries will regard information about weak signals of danger, improvement measures, documentation of work performance etc. which can prove to be safety-critical in given circumstances.

Some may now wonder what is left of the term 'organization' if it is nothing more than a fragmented collection of subcultures. My point here is not to say that organization-wide integration is impossible. There are a number of factors that may provide the basis of integration across boundaries, five of which I will briefly mention. First, national and ethnic origin is obviously not only a source of differentiation, but also of integration. We are born into our national culture and acquire this culture through primary socialization. An organization that is homogenous in this respect is likely to share the overarching frames of reference of the national culture, e.g. language, fundamental values, general social conventions, etc.

Second, all members of an organization have the same company management. The actions, decisions, communication and behavior of senior managers can be interpreted as expressions of the right way to behave and interact in the organization. The promotion of lower-level managers will also be highly symbolic in 
indicating which kind of employees are seen as valuable, and how one should act in order to have a successful career.

Third, organizations over a certain size will have an organization structure, a company website, an intranet, a set of operating procedures, and a management system making rules and other formal documentation available for employees in different parts of the organization. These are examples of a formal context that the members of an organization usually have to relate to in one way or another.

Fourth, most organizations have a set of espoused values describing how key actors would like the organization to be perceived, both by its employees and its surroundings. When these are known among the members of the organization (which is not always the case) they form common points of reference for what is stated as the desired form of behavior.

Fifth, some organizations have experienced crisis, disaster or other key events that stands out in the organization's recent history. The way these are being interpreted by the different groups in the organization may not be characterized by neither clarity nor consistency, but they will still form a point of reference that cuts across the lines of differentiation in the organization.

What is likely to be shared across the subcultures of an organization is thus related to national culture, a general formal context, and key events that have occurred in the organization's recent history. What is not shared are the micro-level experiences that create, recreate and change the informal aspects of organizing. The comments above illustrate that discussions about sharing and differentiation are closely intertwined. The very existence of differences between groups presupposes a level of integration within each of the groups. The important point in this respect is that an empirical question is raised not only by the content of integration, but also by the level of that integration.

\section{From Description to Improvement: How Do We Move from Diagnosis to Treatment?}

One of the questions I have frequently been asked by practitioners is "what is the best way to improve our safety culture?" My answer is always the same: "There is no one best way to improve your safety culture". Selecting the strategy of improvement depends on the problem that needs to be solved, and the kind of improvement practices that are likely to resonate with the people owning the problem. Expecting there to be one, proven approach that works irrespective of company, context, history and problem is like expecting your doctor to be able to prescribe a medicine that is guaranteed to improve your health and wellbeing, irrespective of your symptoms, history of illness and underlying health condition. While I have no doubt that my answer is correct, I cannot help but feel that I should be able to come up with a list of examples of the way different approaches have 
contributed to solving different problems in different contexts, and a more scientific discussion of why efforts to improve safety have succeeded or failed.

This points to what I believe is a gap in safety culture research: the body of research articles describing safety culture by far outnumbers the articles reporting the results of efforts to turn descriptions of safety culture into safety improvements. There are probably many reasons for this. One is that improvement projects are often run by consultants, not researchers. Hence, publishing the projects' results are not a priority task. Another reason is that safety improvement is hard to measure, particularly when it comes to major accident risk, and thus it is hard to convince the editors of scientific journals that the results from improvement projects are worth publishing. This should be seen as a joint challenge to high-risk industries and the research community. There is a need to empirically document improvement efforts with a greater level of scientific rigor and 'objectivity' in order to create a better repertoire of possible safety improvement strategies. There is also a need to connect the field of safety improvement to the general literature on organizational improvement. In my previous publications, I have tried to extract some lessons from the general literature on organizational development that, in my view, can form a platform for improving safety through a cultural approach. The result was a list of ten general principles:

1. Organizational transformation is self-transformation. If we accept the premise that cultures are created from the interaction between people, the various groups and professional communities need to be involved in dialogue to define both problems and solutions.

2. Goals should be moderate and relate to everyday realities. Unless improvement measures can be related to the daily tasks and reality of the problem owners, it will not have lasting effects.

3. Change must be viewed as a long-term project. While the boxes and arrows of an organization chart can be moved in a matter of minutes, changing the way people work requires years of persistence.

4. The goal should not be organization-wide consensus, but creating a common language and understanding between groups. Differentiation between groups can be a vital resource for safety. Multiple perspectives are a source of requisite variety that can increase the chance of weak danger signals being detected somewhere in the organization.

5. Combine 'push' and 'pull'. Top-down change efforts will fail unless there is a motivation for change at the sharp end of the organization.

6. Management initiates and contributes, but the shop floor must be involved in continuous dialogue. Personnel on the ground have expert knowledge on hazards, work processes and situational demands. This must be acknowledged, respected and utilized.

7. Be sensitive to organizational symbolism. For instance, organizational stories are powerful conveyors of culture and can emphasized to illustrate the problems to be solved, or the early wins in the change process. 
8. Gaps between frontstage visions and backstage priorities will derail change processes. If people stop trusting the intentions and truthfulness of managers or coworkers, the change process can have very unpredictable outcomes and negative consequences.

9. Be sensitive to local sense making. Customize change efforts to the different groups that need to be involved to achieve change.

10. Consider the need for change and the realism of objectives. The 'change-or-die' mantra is overrated, particularly when it comes to safety. If you are not sure that you have an organizational problem related to safety, don't start fixing it.

Although these principles are of a rather general nature, I would still like to express a few reservations about their application. Much of the research behind the principles are performed in Scandinavian organizations. The working life tradition in Scandinavia emphasizes worker participation, empowerment and a high level of job security. This is a framework condition that no doubt exerts influence on which improvement strategies are likely to succeed and fail. This means that we should be wary of transporting improvement measures across contexts without consideration of differences in culture and framework conditions.

A final note on cultural change is needed with reference to learning from major accidents and disasters. An important part of safety improvement, as in all other efforts to improve organizations, is to 'unfreeze' the existing structures (Lewin, 1947) before changes can be made. Major accidents provide organizations with the strongest possible motivation to engage in critical reflection on matters related to safety. This introduces the post-accident phase as a key window of opportunity to influence basic safety assumptions. An accident or a disaster leaves the organizations involved shaken to their very foundations. Although there is not necessarily agreement on diagnosis or treatment, there is still an urgent impression that maintaining the status quo is not an option. The shock of the disaster, the investigation reports, media coverage and organizational stories can constitute boundary objects that function as a common point of reference for communication and decision-making that cuts across internal organizational heterogeneity and other organizations in the same industry. For instance, the capsizing of the Alexander Kielland oil rig is still a major reference point for safety in the Norwegian petroleum industry, and few accidents have gained more worldwide attention than that of Deepwater Horizon. This means that major accidents or disasters constitute a source of common experience that may be shared across contexts, as described above. Safety cultures will be strongly influenced by the adverse events that the group(s) have either experienced themselves or can relate to in terms of industry, work situation or profession. Part of a cultural approach to safety improvement involves moving people's horizons of understanding of what can go wrong, and this horizon is strongly influenced by the stories and experiences of major accidents. 


\section{The Downside of Cultural Explanations for Safety}

The cultural approach to safety was the focus of much optimism around 2000, when several companies launched massive safety campaigns. While this optimism is now somewhat downgraded, it is still fruitful to consider the limits to the safety culture approach from time to time.

There is an English saying stating that "no good deed goes unpunished" which essentially means that however good the intentions of an action may be, there will always be some unintended consequence that can cause benevolent actions to backfire. This is also true for the concept of safety culture. One downside lies in the use of culture as an explanatory variable for accidents. Saying that an organization's culture has contributed to creating an accident implies that something was wrong with that particular organization. Attributing causality to the unique characteristics of particular organizations makes it easy to conclude that "it could not happen here", and thus close the door toward learning from other organizations' accidents. Consider the very origins of the concept of safety culture, the Chernobyl accident. The accident shook the nuclear industry to its foundations throughout the world. Without reverting to conspiracy theories, attributing the causes of the accident to the cultural traits of the Soviet system (as well as the particular reactor design) can be a convenient way of reestablishing the belief that the errors that could occur in a Soviet organization were unthinkable in the Western part of the industry. A similar point has been made by Bye, Rosness, and Røyrvik (2016) in their analysis of the use of the term 'HSE culture' in investigation of incidents in the Norwegian petroleum industry. They found that the term 'poor HSE culture' led to premature closure in the search for an accident's causes as some uses of the term entailed little other than simplistic explanations of rule violations. Consequently, the use of safety culture as an explanatory variable in accidents investigations should be used with some caution if the aim is to facilitate learning in other organizations.

Another possible downside of focusing on safety culture lies in the relationship between the 'hard' and 'soft' aspects of safety. Previous research has discussed whether the focus on safety culture can be an excuse for not investing in new technology and developing technological design. This is an important question. Measures directed at controlling behavior are usually cheaper than changing production technology. However, focusing on behavior involves measures that compensate for the existence of a hazard. It is less suitable for removing the source of danger causing the problems in the first place. Focusing resources on safety culture can thus be a source of false security if it replaces the continuous search for safer technology. 


\section{Conclusion}

The initial enthusiasm that surrounded the concept of safety culture around the year 2000 has now (fortunately) waned and has been replaced by a more realistic and mature approach in terms of theoretical grounding and methodical approach. I have argued that a key to taking the next step is to better take into account the boundary processes between groups. The point is that if we do not look for such boundaries and boundary processes, we are likely to overlook them, and if we overlook them we miss a great deal of the dynamics that constitute organizational life. As safety is usually a composite 'product' of the efforts of several groups, the dynamics between integration and differentiation needs to be addressed.

An important next step in safety culture research is to study safety interventions. Creating new knowledge about the improvement of safety by means of a cultural approach will require close collaboration between researchers and problem-owners. There is a need for more long-term research collaboration between academia and industry to ensure the realism and rigor needed to design and document high-quality development processes.

\section{References}

Antonsen, S. (2009a). Safety culture: Theory, method and improvement. Farnham: Ashgate.

Antonsen, S. (2009b). Safety culture and the issue of power. Safety Science, 47(2), 183-191.

Barth, F. (1969). Introduction. In F. Barth (Ed.), Ethnic groups and boundaries: The social organization of culture difference. Oslo: Universitetsforlaget.

Bye, R. J., Rosness, R., \& Røyrvik, J. O. D. (2016). 'Culture' as a tool and stumbling block for learning: The function of 'culture' in communications from regulatory authorities in the Norwegian petroleum sector. Safety Science, 81, 68-80. https://doi.org/10.1016/j.ssci.2015.02.015.

Cox, S., \& Flin, R. (1998). Safety culture: Philosopher's stone or man of straw? Work Stress, 12, 189-201.

Crozier, M. (1964). The bureaucratic phenomenon. Chicago: University of Chicago Press.

Datta, A., \& Brickell, K. (2009). "We have a little bit more finesse, as a nation": Constructing the Polish worker in London's building sites. Antipode, 41(3), 439-464. https://doi.org/10.1111/j. 1467-8330.2009.00682.x.

Guldenmund, F. W. (2000). The nature of safety culture: A review of theory and research. Safety Science, 34, 215-257.

Johannessen, S. (2013). Politikultur: Identitet, makt og forandring i politiet. Trondheim: Akademika.

Lewin, K. (1947). Frontiers in group dynamics. In D. Cartwright (Ed.), Field theory in social science. London: Social Science Paperbacks.

Mintzberg, H. (1983). Structure in fives: Designing effective organizations. Englewood, New Jersey: Prentice Hall.

Schein, E. H. (1996). The three cultures of management: Implications for organizational learning. Sloan Management Review, 38(1), 9-20.

Turner, B. (1978). Man-made disasters. London: Wykenham Science Press.

Turner, B. A., \& Pidgeon, N. F. (1997). Man-made disasters (2nd ed.). Oxford: Butterworth Heinemann. 
Wasilkiewicz, K., Albrechtsen, E., \& Antonsen, S. (2016). Occupational safety in a globalised construction industry: A study on Polish workers in Norway. Policy and Practice in Health and Safety, 14(2), 128-143.

Wenger, E. (1998). Communities of practice: Learning, meaning, and identity. Cambridge: Cambridge University Press.

Zohar, D. (1980). Safety climate in industrial organizations: Theoretical and applied implications. Journal of Applied Psychology, 65(1), 96-102.

Open Access This chapter is licensed under the terms of the Creative Commons Attribution 4.0 International License (http://creativecommons.org/licenses/by/4.0/), which permits use, sharing, adaptation, distribution and reproduction in any medium or format, as long as you give appropriate credit to the original author(s) and the source, provide a link to the Creative Commons license and indicate if changes were made.

The images or other third party material in this chapter are included in the chapter's Creative Commons license, unless indicated otherwise in a credit line to the material. If material is not included in the chapter's Creative Commons license and your intended use is not permitted by statutory regulation or exceeds the permitted use, you will need to obtain permission directly from the copyright holder. 